\title{
Pueblos sin religión: la falacia de la controversia de Valladolid
}

\section{Peoples Without Religion: the Fallacy of Valladolid Controversy}

\author{
Daniel Montañez Pico ${ }^{1}$ \\ UNAM (México)
}

Recibido: 06-04-16

Aprobado: 26-07-16

\section{Resumen}

De la multicitada controversia de Valladolid sobre la humanidad de los indios sabemos realmente muy poco debido a la falta de fuentes y documentos. Sin embargo, se ha convertido con el paso del tiempo en un referente historiográfico fundamental para comprender el dominio hispano sobre América durante el periodo colonial. En este trabajo tratamos de abonar al debate una sencilla idea: no existió tal controversia sobre la humanidad de los indios en Valladolid, lo que existió fue una disputa sobre los modos de colonizar a los pueblos indígenas del continente americano. Para sostener esta idea, en un primer momento expondremos el problema de la comprensión occidental de los pueblos indígenas bajo la idea de su caracterización como "pueblos sin religión” necesitados de una tutela permanente $y$, en un segundo momento, caracterizaremos el debate de Valladolid como una controversia que, partiendo de ese principio fundamental, nunca cuestionó la máxima más cruel y el principio de legalidad esencial del colonialismo: el proceso de evangelización.

Palabras-clave: Controversia de Valladolid, pueblos indígenas, pueblos sin religión, evangelización, colonialismo.

\footnotetext{
${ }^{1}$ (danielm9876@hotmail.com.). Estudiante de Doctorado en Estudios Latinoamericanos, UNAM. Maestría en Estudios Latinoamericanos, UNAM. Licenciatura en Antropología Social y Cultural, Universidad de Granada. 


\begin{abstract}
Due to the lack of sources and documents we really know very Little about the oft Valladolid controversy on the humanity of the Indians. However, it has become over time a fundamental historiographical reference for understanding the Hispanic dominion over America during the colonial period. In this paper we try to pay the discussion a simple idea: there was no such controversy on the humanity of the Indians in Valladolid, which there was a dispute over ways to colonize indigenous peoples of the Americas. To support this idea, at first we will discuss the problem of the Western understanding of indigenous peoples under the idea of its characterization as "people without religion" in need of a permanent guardianship, and, in a second moment, characterize the debate of Valladolid as a controversy who, starting with this fundamental principle, never questioned the cruelest maximum and the essential principle of legality of colonialism: the process of evangelization.
\end{abstract}

Key-words: Controversy of Valladolid, indigenous peoples, peoples without religion, evangelism, colonialism

\title{
1. Un proyecto pedagógico sobre pueblos sin religión
}

\begin{abstract}
"Aunque aisladas dentro de la inmensidad espacial y cultural, ajena y hostil, a las ciudades cometía dominar y civilizar su contorno, lo que se llamó primero 'evangelización' y después ‘educar'. Aunque el primer verbo fue conjugado por el espíritu religioso y el segundo por el laico y agnóstico, se trataba del mismo esfuerzo de transculturación a partir de la lección europea” (Rama, A. 18:1984)
\end{abstract}

Los pueblos indígenas de América fueron concebidos como contenedores vacíos. Así como su territorio fue imaginado como un espacio libre que podía ser "descubierto", sus habitantes también eran humanos desahuciados de la existencia. Formas sin contenido. De esta forma se imaginó el territorio y sus comunidades, una sola unidad natural, exótica, que revitalizaba antiguos sueños insertos en lo más profundo de las mentalidades del mundo de la cristiandad. Estaban ahí, esperando, a que una civilización superior llegara para dotarles de contenido a sus primitivas formas. Esta es la ideología que los occidentales vertieron sobre América y sus habitantes desde 1492.

La crítica a la idea de "contenedor vacío" es uno de los nudos centrales de la pedagogía de la liberación surgida en el siglo XX, aunque se puede rastrear en pensadores y pensadoras de siglos anteriores. La tesis básicamente plantea que en el mundo moderno se generó la idea de que los infantes eran seres vacíos que había que ir modelando y llenando de saberes adecuados para el correcto despliegue y evolución de la sociedad. La escuela sería la institución 
por antonomasia encargada de otorgar el contenido adecuado a sus formas y se dejaría a la familia (monógama y nuclear) la instrucción en cuestiones consideradas de índole privada relacionadas con ciertas partes de la moral y la ética social. La pedagogía de la liberación se instalaría en un paradigma antagónico donde todos los sujetos son concebidos como seres completos y la educación forma parte de la comunidad en su totalidad. De sus postulados emanarían experimentaciones y procesos de aprendizaje horizontales y colectivos con fundamento en cada comunidad y no industrias de domesticación social que anulan la libertad ontológica y la capacidad de emancipación y liberación del ser humano. En el rescate que Jacques Rancière realiza sobre la filosofía pedagógica que Joseph Jacotot construyó a principios del siglo XIX se plantea la crítica en los siguientes términos:

"La explicación no es necesaria para remediar una incapacidad de comprensión. Todo lo contrario, esta incapacidad es la ficción que estructura la concepción explicadora del mundo. El explicador es el que necesita del incapaz y no al revés, es él el que constituye al incapaz como tal. Explicar alguna cosa a alguien, es primero demostrarle que no puede comprenderla por sí mismo. Antes de ser el acto del pedagogo, la explicación es el mito de la pedagogía, la parábola de un mundo dividido en espíritus sabios y espíritus ignorantes, espíritus maduros e inmaduros, capaces e incapaces, inteligentes y estúpidos" (Rancière, J. 2002:8, negritas mías).

Mencionar esta crítica a la pedagogía moderna basada en el precepto de contenedores vacíos y llenos, sustentada sobre una concepción antropológica del ser humano desustanciada de su constitución vital, de su memoria genética, cultural, material, etc., no es un ejercicio vano en este espacio. La conquista y evangelización de América fue el primer proyecto pedagógico moderno implementado a gran escala. Inauguró el principal nudo de discusión que hoy debate la pedagogía de la liberación. Los misioneros generaron un método y un espíritu que fue el principal inspirador tanto para los proyectos pedagógicos nacidos en la ilustración como los nacidos en los ciclos populistas del siglo XX. La escuela moderna tal como hoy la conocemos fue la secularización del gran proyecto evangelizador del siglo XVI. Napoleón imaginó a todas las escuelas de Francia dictando los mismos contenidos e izando la bandera y cantando el himno de la nación al mismo tiempo antes de iniciar sus actividades. La misa se cambió por este ritual que fue incluso más homogeneizador que el anterior en el que al menos cabían, en algunos casos, diferencias regionales. Más tarde las escuelas rurales de América Latina tomarían la actividad misionera del siglo XVI como su principal antecedente y fuente de inspiración. El caso de las Misiones Culturales Rurales en el México posrrevolucionario, donde el mismo espíritu utópico y ambicioso de los evangelistas fue recogido por sus maestros en nombre de la modernización, es relevante: 


\begin{abstract}
"En palabras de José Vasconcelos: 'Para comenzar designamos a los nuevos maestros con el nombre de misioneros, en honor de los verdaderos civilizadores que ha conocido el Nuevo Mundo' [...] En 1921, José Vasconcelos personifica las aspiraciones educativas de la Revolución como ningún hombre llegó a encarnar, digamos, la reforma agraria o el movimiento obrero [...] La educación ya no se entendió como una educación de una clase media urbana, sino la forma única que en México puede entenderse: como una misión religiosa, apostólica, que se lanza y va a todos los rincones del país, llevando la buena nueva de que México se levanta de un letargo, yergue y camina" (Sierra, A. 11:1973)

"Su misticismo, su personal admiración por San Francisco de Asís, en fin, su cristianismo, hicieron a Vasconcelos concebir a los misioneros culturales como una obra mesiánica y redentora a la manera de la salvación evangelizadora cristina. La redención mediante la cultura fue la consigna a cumplir por las Misiones Culturales Rurales" (Hicks, E. 25:1984).
\end{abstract}

Esta primera desustanciación de la humanidad a gran escala fue vertida sobre los pueblos indígenas de América bajo la idea de que eran "pueblos sin religión" (cuestión que más tarde se secularizaría y pasaría a denominarse "pueblos sin civilización", "pueblos sin cultura", "pueblos sin desarrollo", "pueblos sin democracia", etc.). Anteriormente también se habían considerado inferiores a otros pueblos por rezar al "Dios equivocado", aún conociendo la existencia del cristianismo. Sin embargo, estos pueblos fueron considerados "puras bestias" (pueblos del África negra) o "enemigos" (árabes y cristianos paganos), nunca "pueblos sin religión". Los herejes tenían la religión equivocada, pero no carecían de esa capacidad humana y podían llegar a ser de nuevo aceptados dentro de la comunidad cristiana si se convertían a la "verdadera fe". Tenían esa capacidad. Los pueblos indígenas parecían no haberla desarrollado todavía y se mostraban, como dice Colón textualmente: "pueblos sin secta", "buenos servidores", es decir, vasallos por naturaleza ${ }^{3}$.

\footnotetext{
${ }^{2}$ En esta época el significado de secta estaba más ligado al origen etimológico del verbo latino sequi (seguir) que el más conocido en nuestra actualidad, vinculado quizás con el verbo latino secare (cortar, separar), en el sentido de ser grupos separados y automarginados de las creencias religiosas oficiales y/o mayoritarias. "Secta", en el lenguaje cotidiano del siglo XV, servía en muchos casos como sinónimo de religión, en el sentido de un grupo de personas que siguen un dogma, líder espiritual, etc. Carecer de religión en esta época y en este contexto específico sería caer en un "estado de naturaleza" que, siguiendo al profesor Francisco Castilla Urbano, era algo digno de admiración, cercano a la imagen que se tenía sobre las sociedades del tiempo del cristianismo primitivo, pero insuficiente, dentro del esquema organicista e inmovilista de la escolástica hispana, para que desde esa perspectiva se propusieran auténticas defensas ante los procesos de conquista, evangelización y esclavitud de los pueblos nativos de África y América (Castilla, F. 442: 1995).

3 "Ellos andan todos desnudos como su madre los parió, y también las mugeres, aunque no vide más de una harto moça. Y todos los que yo vi eran todos mancebos, que ninguno vide de edad de más de treinta años. Muy bien hechos, de muy fermosos cuerpos y muy buenas caras, los cabellos gruessos cuasi como sedas de cola de cavallo, y cortos. [...] son de la color de los canarios, ni negros ni blancos [...] Ellos no traen armas ni las conocen, porque les amostré espadas y las tomavan por el filo y se cortavan con ignorancia [...] Ellos deven ser buenos servidores y de buen ingenio, que veo que muy presto dizen todo lo que les dezía. Y creo que ligeramente se harían cristianos, que me pareció que ninguna secta tenían" (Colón, C. 107:2009).
} 
"Durante su primer viaje, Colón permaneció obsesionado por el descubrimiento de Catay y Cipango, en la trayectoria de una de sus lecturas predilectas, el Libro de las maravillas de Marco Polo. Pero obviamente los hombres descubiertos no correspondían con las descripciones del viajero veneciano. Acudió pues Colón a otro mito procedente de la visión medieval de los tártaro-mongoles: los hombres sin religión, carentes de cultos idolátricos y diabólicos, adeptos de un monoteísmo natural y por tanto fáciles de convertir, como habían demostrado Ramón Llul en el Llibre del gentil e los tres savis y Don Juan Manuela en el Libro de los estados. A su llegada a las Lucayas, apuntaba colón en su diario, el 12 de octubre, que los indígenas se convertirían fácilmente porque, al parecer, 'ninguna secta tenían'. Pero Vaz de Caminha, el cronista de la expedición de Pedro Álvares Cabral que descubrió Brasil en la primavera de 1500, decía exactamente lo mismo a propósito de los tupis desnudos y salvajes de la costa de la Tierra de la Vera Cruz: 'segundo parece, nao tem, nem entendem em nenbuma crença'. En la trayectoria de las ilusiones bajomedievales, españoles y portugueses estimaban que el cristianismo romano se extendería fácilmente entre los pueblos 'sin secta' e incluso entre aquellos idólatras cuyas creencias erróneas podrían ser arrancadas sin mayores dificultades gracias a la argumentación ayudada por la coacción” (Milhou, A. 144/145: 1998).

Cristóbal Colón ha sido caracterizado por algunos autores como el "último de los viajeros medievales" (Weckmann, 32: 1994). Esta tradición literaria incluye relatos de viajes cuya realización misma es puesta en duda y donde predominan los hechos fantásticos como fueron los "Travels of Sir John Mandeville" (1371), hasta el más conocido "Il Milione " de Marco Polo (1116) que mezcla ambas vertientes de realidad y ficción. Este último libro, del que el mismo Cristóbal Colón llegó a tener un ejemplar basado en una traducción latina de Francesco Pipino publicada en Amberes en 1485, fue junto a "Travels of Sir John Mandeville", "Las andanças e viajes de un hidalgo español" de don Pedro Tafur (1436) y la "Embajada al gran Tamorlán” de Ruy González de Clavijo (1406), el corpus de viajes medievales más publicado y conocido en el mundo hispánico que pudieron haber influenciado y "prestado ciertos procedimientos narrativos y descriptivos con los cuales los primeros conquistadores dan cuenta de una realidad nueva a la que un número reducido de destinatarios puede tener acceso" (Rodríguez, J. 16:2010). Teniendo en cuenta esta tradición podríamos interpretar que esta primera categorización de "pueblos sin religión" podría derivarse de la lectura de estos relatos fantásticos, bebiendo de las caracterizaciones antropológicas que se habían hecho anteriormente por misioneros y conquistadores de pueblos asiáticos

\footnotetext{
"No le conozco secta ninguna y creo que muy presto se tornarían cristianos, porque ellos son de muy buen entender" (Colón, C. 115:2009).

“... sin ninguna secta que yo conozca, que fasta oy aquestos que traigo no e visto hazer ninguna oración, antes dizen la Salve y el Ave María con las manos al cielo como le amuestran y hazen la señal de la cruz. Toda la lengua también es una y todos amigos, y creo que sean todas estas islas y que tengan guerra con el Gran Can, a que ellos llaman Cavila y a la provincia Bafan” (Colón, C. 129:2009).
} 
y aborígenes de islas como las Canarias. Los proyectos de evangelización en pueblos asiáticos ensayados por franciscanos en el siglo XIII en tierras del Gran Kahn, han sido analizados por George Baudot. Su investigación alumbra al respecto:

“... otro religioso franciscano, fray Guillermo de Rubruckis o Rubrigenio dedicaría tres años, entre 1253 y 1256, a un extenso viaje por Extremo Oriente, llegaría hasta Qarqorum, visitando la corte del gran Khan Möngke, y a su regreso redactaría un valiosísimo testimonio 'etnográfico': el Itinerarium ad partes orientales [...] Evidentemente, el trasfondo utopista era más o menos el mismo. Una finalidad política impregnada de esperanza escatológica guiaba estas cuidadosas descripciones de las sociedades mongoles que se analizaban esperando pudieran ofrecer cierta facilidad de conversión y autorizar así una cristianización acelerada del Asia gengiskánida. El programa era político: rodear y sitiar el Mediterráneo musulmán para aplastar al Islam, liberar los Santos Lugares y permitir la fundación de la Nueva Jerusalén y la venida del reino milenario, prefacio al Juicio Final. Cierto es que estas obras manifestaban algunas prudencias respecto a la facilidad del proyecto, pero la imagen procurada de la sociedad mongol y de su humanidad llevaba íntimamente connotada la organización discursiva a priori de esta visión metahistórica" (Baudot, Georges 244/245:1996).

Desde un punto de vista más filosófico y político, Nelson MaldonadoTorres ha caracterizado esta afirmación como la primera categorización racista en términos modernos, en el sentido de que se trata de la primera vez que se pone sistemáticamente en entredicho la humanidad de un gran conjunto de pueblos (Maldonado-Torres, N. 3: 2005). Bajo su punto de vista en la época en la que están afirmando la cuestión de que se trata de "pueblos sin secta" puede ser entendida como sinónimo de "pueblos sin alma" negando así una condición humana universal que convertía por naturaleza a estos pueblos en unos idealizados "perfectos servidores":

\footnotetext{
"Referirse a los indígenas como sujetos sin religión los saca aparte de la categoría de lo humano. Como la religión es algo universal en los humanos, la falta de la misma no denota la falsedad de la proposición , sino al contrario, el hecho de que hay sujetos que no son del todo humanos en el mundo [...] Los sujetos sin religión no están equivocados, tanto como están, según esta concepción, ontológicamente limitados. Al juzgar a los indígenas como sujetos "sin secta" Colón altera la concepción medieval sobre la 'cadena del ser' y hace posible pensar sobre el "condenado" ya no en términos exclusivamente cristianos y teológicos sino más bien antropológicos y modernos. A los condenados modernos les faltará no sólo la verdad, sino también parte fundamental de lo que se considera ser humano. Su falta no es tanto un resultado de su juicio, como un problema mismo de su ser. La colonialidad del poder nace así pues simultáneamente con la colonialidad del ser [...] la aseveración de Colón
} 
sobre la falta de religión en los indígenas introduce un sentido antropológico del término. A la luz de lo discutido aquí habría que añadir que el sentido antropológico del término está también vinculado a una muy moderna de clasificar humanos: la clasificación racial. Con un solo plumazo, Colón lanza el discurso de la religión del ámbito teológico al de una antropología filosófica moderna que distingue entre distintos grados de humanidad con identidades fijadas en lo que luego se conocerá como razas. Aunque suene exagerado, quizás no está muy lejos de la verdad decir que Colón fue a la vez no sólo el primer teórico moderno de la religión sino también el primer racista en Occidente" (Nelson Madonado-Torres citado en Grosfoguel, R. 45: 2013).

Esta visión iba generalmente acompañada de aseveraciones sobre la "bondad" y "buen obrar" de los pueblos indígenas que para muchos y muchas constituyen el germen de la idea del "Buen Salvaje" que más adelante emergió en la ilustración europea en el pensamiento de autores como Rousseau. Pero se diferencia de la misma en algunas cuestiones. Para los misioneros del siglo XVI el modo de vida de los pueblos indígenas podía recordar al del cristianismo primitivo y ello era celebrado como la posibilidad de sobrevivir o retrasar un posible apocalipsis inminente (la llegada del Millenium). Dado que no conocían la "verdadera fe", era posible considerar que, pese a sus idolatrías, eran pueblos que no vivían en el pecado, pero ello no implicaba que no tuviesen que ser instruidos en la religión cristiana para mayor gloria de Dios. En la idea moderna secular de "Buen Salvaje" los humanos considerados primitivos son ya en sí mismo un modo de vida completo y bueno por naturaleza. La civilización vendría a corromper a estas sociedades que vivían en un estado de naturaleza diferente al imaginado por Thomas Hobbes, un estado de libertad y plenitud humanas. Una fórmula que sirve para señalar las miserias de la sociedad moderna pero que a la vez convierte en exóticos los modos de vida de otros pueblos y reduce su vida colectiva a un impasse en el tiempo. Bajo el modelo del siglo XVI, la bondad originaria de los pueblos ha de ser aprovechada para la construcción de una ideal sociedad cristiana y bajo la idea secular del siglo XVIII habría de ser conservada estáticamente en el tiempo como si se tratara de especies en peligro de extinción. En cualquiera de los casos persiste sobre estos pueblos una idea de tutela, sea para transformarlos o para conservarlos, que perdura hasta nuestros días en las políticas públicas y las legislaciones creadas hacia estos pueblos en el continente. 


\section{EI debate: think tank de la Conquista}

La necesidad tutela de los pueblos indígenas fue un principio filosófico, jurídico y político fundamental para legitimar la conquista de América. No obstante, hubo una serie de debates en la Península Ibérica y Europa durante el siglo XVI que trataron de delimitar sus procedimientos y alcances políticos y jurídicos. Estos debates han sido señalados como "la primera vez que un Imperio puso a debate los alcances de sus conquistas" o como "la primera vez que se debatía sobre la humanidad de ciertos grupos humanos". Considero falsas y problemáticas ambas posturas.

En cuanto a la primera aseveración, considero que fue el acontecimiento que supuso para los europeos toparse con una gran masa continental que no entraba en sus planes y cosmovisiones la que propició el debate. Un hecho tan extraordinario no tenía precedentes jurídicos ni de ningún tipo de donde poder establecer un legítimo proceso de conquista. Pese a existir conocidos antecedentes desde donde podría comenzar a tratar de ser comprendido, como la supremacía papal sobre las islas o las sagradas guerras contra los árabes y las cruzadas, se trataba de un acontecimiento de naturaleza nueva y diferente que rompía con varios esquemas civilizatorios de la comprensión medieval cristiana del mundo. Fue el acontecimiento americano el que impuso el debate y no el imperio castellano que por misericordia y buena voluntad reunía a sus intelectuales para debatir el alcance ético de su empresa. El debate radicaba en cómo legitimar algo que no había sido aún posible legitimar: la conquista y homogeneización de un continente y sus habitantes los cuales nunca habían provocado ni causado daño alguno a la civilización cristiana (no podían ser considerados de ningún modo creíble como iustus hostis).

En cuanto a la segunda aseveración, considero que es más problemática todavía. Se trata de una estereotipada construcción historiográfica que ha tenido un alcance político considerable que no se puede desdeñar y que en gran medida se basa en intuiciones ciertas. Sin embargo, los estudiosos que se han dedicado al tema extensamente no han podido encontrar evidencias claras de esta cuestión. Por un lado "archivístico" Lewis Hanke, gran recopilador de fuentes de esta época y en concreto de estos debates, reconoce que es imposible conocer qué fue y en qué términos se discutió en el mayor y multicitado cónclave de Valladolid entre 1550 y 1551 , que además no tuvo nunca el juicio final definitivo que se esperaba ${ }^{4}$. Su rastreo sobre la temática alumbra que la Corona estuvo pidiendo

4 Entre los pocos documentos que podemos encontrar sobre la cuestión está el resumen que encomendaron los 14 jueces de la controversia a Domingo de Soto sobre la primera ronda de debates, que fueron leídos como inicio de la segunda ronda. En el resumen, el autor introduce un prólogo en el que alumbra cuestiones acerca del ambiente en el que se daban las discusiones, anotando algunas anécdotas como las referidas a que Juan Ginés de Sepúlveda exponía sus ideas de memoria y Bartolomé de Las Casas usaba más tiempo porque leía sus escritos al completo (Soto, D. 170:1985). También anota opiniones personales sobre la verdadera esencia de las discusiones que apoyan el 
los informes detallados de las discusiones, los cuales nunca llegaron a realizarse por parte de quienes estaban encargados de ello (Hanke, p. 121 y ss.: 1976). Las principales fuentes sobre este cónclave son escritos posteriores que hacen alusión a sus discusiones, sobre todo de fray Bartolomé de Las Casas y Juan Ginés de Sepúlveda". Por otro lado "textual", el profesor José María Gallegos Rocafull después de revisar arduamente los escritos de los intelectuales que acudían a estos debates, concluye que ni a los más conservadores y defensores de los encomenderos se les puede atribuir que no considerasen a los indios como seres humanos. Alude a la propia filosofía tomística y su organicismo donde se presenta a los pueblos indígenas siempre como necesarios "siervos a natura" más que como animales. Esta filosofía humanista, progresista o conservadora, imposibilitaba hacer tal aseveración, encontrando siempre metáforas o comparaciones animalísticas, pero nunca la afirmación de que se trataba de seres no-humanos. Para el autor, la idea de que los pueblos indígenas no eran humanos correspondía más bien a un rumor generalizado sobre todo entre los encomenderos para poder seguir legitimando la posesión de indios como siervos y esclavos así como la ocupación de sus tierras. Concluye nuestro autor con la siguiente tesis:

"Debidamente interpretados, aun los textos más negativos no permiten suponer
que en España o en las Indias se opinase con todo rigor que los indios no
fueran hombres [...] en el fondo lo que quieren decir es simplemente que los
indios no deben tener los mismos derechos que los españoles $[\ldots]$ se hubieran
visto obligados, entre otras cosas, a las siguientes: $1^{\mathrm{a}}$ a elaborar el concepto
correspondiente a esa nueva especie de seres, que no cabrían en el de hombres,
ni tampoco en el de ninguno de los animales conocidos; $2^{\mathrm{a}}$ a oponerse a
rajatabla no ya al matrimonio de españoles con indias, sino a todo trato sexual
con ellas, pues hubiera sido incurrir en el pecado de bestialidad; $3^{\mathrm{a}}$ a desistir
de convertirlos al cristianismo, lo que ya en 1517 fue considerado como una
herejía; y $4^{\mathrm{a}}$ A dar un sentido completamente distinto a la legislación de las
Indias, cuyo supuesto fundamental es que los indios son hombres, aunque
necesitados de protección y tutela" (Gallegos, J. M. $14 / 15: 1974$, negritas mías).

argumento de fondo que estamos tratando de exponer en este texto: "El punto que vuestras señorías, mercedes y paternidades pretenden aquí consultar, es, en general, inquerir e constituir la forma y leyes cómo nuestra sancta fe católica se pueda predicar e promulgar en aquel nuevo orbe que Dios nos ha descubierto, como más sea a su sancto servicio, y a examinar qué forma puede haber cómo quedasen aquellas gentes subjectas a la Majestad del Emperador nuestro señor, sinlesión de su real conciencia, conforme a la bulla de Alejandro. Empero, estos señores proponientes no han tratado esta cosa así, en general y en forma de consulta; mas, en particular, han tractado y disputado esta cuestión, conviene saber: si es lícito a su Majestad hacer guerra a aquellos indios antes que se les predique la fe, para subjectallos a su Imperio, y que después de subjectados puedan más fácil y cómodamente ser enseñados y alumbrados por la doctrina evangélica del conocimiento de sus errores y de la verdad cristiana" (Soto, D. 170:985).

${ }^{5}$ Véanse las Apologías publicadas por Editora Nacional en Madrid en 1975, también publicadas por Alianza Editorial en Madrid en 1988 en su volumen noveno de las Obras Completas de Las Casas. 
¿Por qué realizo este apunte? ¿no podría parecer un gesto negativo y conservador hacia las luchas de los pueblos indígenas de América? Considero que no. A los pueblos indígenas se les trató y se les trata por debajo de la línea de concepción de lo humano, sobre eso no cabe ninguna duda. Hacer estas acotaciones nos sirve para romper con el mito de Valladolid como el cónclave donde se debatía si los indios eran humanos o no. ¿Por qué romper con este mito? Porque nos encierra epistemológicamente. Nos conduce a pensar que en estos debates había una suerte de "atacantes" y "defensores" en vez de poder vislumbrar la realidad de un conjunto de intelectuales trabajando y pensando para el imperio castellano, lo que hoy se conoce como un think tank. En estos debates se discutía sobre cómo legitimar y direccionar la conquista y evangelización de los pueblos indígenas, nunca se ponía en entredicho su hecho originario y fundamental (amén de que los debates se hacían, obviamente, a posteriori de los hechos). Esta forma de entender la disyuntiva nos puede abrir otros caminos investigativos donde se estudien ejemplos de relación entre europeos y nativos americanos que no estuvieran basados en una defensa caritativa y tutelar sino en un apoyo mutuo, solidario y horizontal, honesto y sincero con lo real. Este podría ser el caso de Gonzalo Guerrero, soldado hispano naufragado en la península del Yucatán que terminó viviendo en comunidades mayas donde llegó a tomar roles sociales de importancia y a unirse a una mujer con quien tuvo hijos. Hernán Cortés en persona llegó a requerir su presencia para usarle como traductor, pero recibió la negativa de Gonzalo que prefirió quedarse junto a su nuevo pueblo. Nuestro personaje terminó liderando facciones mayas frente a la conquista y le dieron muerte en el combate que trataba de contener el avance de la invasión del ejército castellano capitaneado por Pedro de Alvarado en el territorio hoy conocido como Honduras ${ }^{6}$.

¿Qué sucedería si estableciéramos a un personaje como Gonzalo Guerrero como ejemplo de "defensor" de los indios en vez de a fray Bartolomé de Las Casas? Considero que este giro del pensamiento nos abriría oportunidades de pensar la política y lo político en la conquista de América mucho más fecundas que quedarnos con la idea de "evangelización pacífica" de Bartolomé de Las Casas como "máxima conciencia crítica de un europeo en América" (Dussel, E. 204: 2007). Gonzalo Guerrero, aunque no escribió grandes tratados, expuso su cuerpo hasta la muerte, lo que demuestra una gran conciencia solidaria y crítica que nunca pudo sostener Bartolomé de Las Casas. Sus letras fueron sus actos y "uno es lo que uno hace no lo que uno dice". Contribuir a este giro, análisis y proyecto de investigación significa abrir una posibilidad epistemológica y

\footnotetext{
${ }^{6}$ Sobre la vida de Gonzalo Guerrero se han escrito varias novelas históricas e investigaciones parciales. Que sepamos la primera tesis doctoral dedicada completamente a este personaje es la de Salvador Campos Jara de la Universidad de Huelva titulada "Estudio sobre la evolución del personaje de Gonzalo Guerrero". En la página web de este autor se puede acceder a material diverso sobre esta figura: http://gonzaloguerrero.orgfree.com.
} 
política necesaria. Ojalá algún día los libros de texto de Nuestra América puedan recoger ésta y otras historias semejantes para poder compartir con nuestros y nuestras jóvenes experiencias de auténtica interculturalidad, defensa de lo común y de nuestros pueblos en el continente. La tutela, vertical y caritativa, ni ha sido ni puede ser la única posibilidad de crítica frente a la imposición y dominación ajena.

Caracterizaremos brevemente, desde esta perspectiva, las posiciones que hubo en los debates del siglo XVI en relación a los pueblos indígenas y la conquista de América.

\subsection{Los que atacan}

En este grupo se ha situado históricamente como figura sobresaliente a Juan Ginés de Sepúlveda, como líder de toda una serie de autores y posiciones radicalmente negativas frente a la relación de los cristianos con los pueblos indígenas. Esta sería la perspectiva de los defensores de la postura de los encomenderos, un grupo social fuerte en los comienzos de la conquista que lideró y definió la principal célula de la sociedad colonial: la encomienda. Una estructura económica y política de dominación sobre los pueblos indígenas de América que aun persiste bajo la forma de latifundios y haciendas hasta nuestros días. La principal crítica que tuvieron los encomenderos fue el maltrato que daban a los indígenas que les quedaban como siervos en las encomiendas, lo cual rompía el vínculo de vasallaje que les unía a ellos por el cual habían de tutelar su conversión al cristianismo y daba lugar a que pudieran ser denunciados como tiranos. Este grupo de intelectuales trató de defender tanto el trato violento como la extracción de recursos naturales del continente.

Los principales argumentos provinieron de la teoría aristotélico-tomista sobre la "servidumbre a natura". Como ya hemos comentado se consideraba bajo este punto de vista que los siervos cumplían un papel social importante para el funcionamiento del conjunto de la sociedad y la consecución del "bien común" y que éste era un papel que por mandato divino se expresaba a través del derecho natural. Lo tenían que ejercer por su propio bien y el de toda la comunidad cristiana. Fíjese que aquí hay un elemento diferente del que más tarde en el absolutismo a través de los pensadores protestantes se impondrá: el derecho divino se expresa a través del derecho natural y no directamente como "gracia". Esto quiere decir que para escrutar los designios divinos había que proceder a un sistema de indagación en el derecho natural que se expresaba en la arena cotidiana de las relaciones sociales existentes. Esta intermediación entre el derecho y la vida no existirá bajo el sujeto soberano que por "gracia de Dios" es fuente inapelable de derecho, como tampoco existirá en su versión secularizada y plenamente moderna: el positivismo del Estado. Para Michel 
Foucault la sustitución del método de la "indagación" por el del "examen" de los hechos a la luz de la ley positiva marcaría el camino hacia una concepción moderna de lo jurídico (Foucault, M. p. 101 y ss.: 1986).

De esta forma estos autores tuvieron que indagar en el derecho natural y las relaciones sociales para poder sustentar la tesis de la servidumbre natural de los pueblos indígenas y legitimar así al núcleo de poder económico y político que estaban defendiendo. El fundamento era, obviamente, sustentar la idea de una inferioridad natural de los pueblos indígenas sobre lo que se construiría todo lo demás. Esta inferioridad estaba basada en la interpretación de los modos de vida de los pueblos indígenas como formas bárbaras y paganas de sociedad. Los argumentos más utilizados fueron la exposición de los sacrificios humanos y el canibalismo que estos pueblos cometían contra las leyes de la naturaleza entendida desde la cosmovisión cristiana. Dicha inferioridad no permitiría la conversión al cristianismo - misión sagrada y sustento jurídico de la conquistade estos pueblos por una vía pacífica, sería necesario y legítimo el uso de la fuerza.

Debajo de este argumento, Enrique Dussel (196:2012) ha interpretado que se encuentra el mito fundante de la modernidad, por el cual se justifica cualquier acción de conquista a través de la justificación de que se expande la "verdadera fe" que más tarde sería formulada como "verdadera civilización", "verdadero desarrollo", "verdadera democracia", etc. Un mito donde una civilización define lo correcto y apto para las demás y a cambio de llevarles e inyectarles - por las buenas o las malas- esta noticia se legitima cualquier proceso de despojo y destrucción de sus saberes ancestrales. Cerremos con una imponente frase de Juan Ginés de Sepúlveda que resume esta ecuación:

\footnotetext{
"Porque escrito está en el libro de los Proverbios: 'El que es necio servirá al sabio'. Tales son las gentes bárbaras é inhumanas, ajenas á la vida civil y á las costumbres pacíficas. Y será siempre justo y conforme al derecho natural que tales gentes bárbaras se sometan al imperio de príncipes y naciones más cultas y humanas, para que por sus virtudes y la prudencia de las leyes, depongan la barbarie y se reduzcan a vida más humana y al culto de la virtud" (Sepúlveda, J.G. 85:1987) “¿Qué cosa pudo suceder á estos bárbaros más conveniente ni más saludable que el quedar sometidos al imperio de aquéllos cuya prudencia, virtud y religión los han de convertir de bárbaros, tales que apenas merecían el nombre de seres humanos, en hombres civilizados en cuanto pueden serlo; de torpes y libidinosos, en probos y honrados; de impíos y siervos de los demonios, en cristianos y adoradores del verdadero Dios? [...] Por muchas causas, pues, y muy graves, están obligados estos bárbaros á recibir el imperio de los españoles conforme á la ley de la naturaleza, y á ellos ha de serles todavía más provechoso que á los españoles, porque la virtud, la humanidad y la verdadera religión son más preciosas que el oro y que la plata" (Sepúlveda, J.G. 133:1987).
} 


\subsection{Los que "defienden"}

"Frente al conquistador, con sus gritos e injurias como única palabra y frente al discurso justificador de los ideólogos de la conquista en el que aún resuena el 'griterío', se organiza la obra del padre Las Casas. Su planteo es simple: se ha de poner límites a la autoafirmación del dominador y ello será únicamente posible reconociendo al dominado su naturaleza racional, viéndolo como criatura tan necesitada en su ignorancia de la salvación, como el otro, en su ansia de posesión y dominio. La relación dominador-dominado ha de ser organizada desde el plan de la salvación o de la condenación de las almas, más, para eso, el dominador deberá trocar el 'griterío' por la 'palabra' que seguirá siendo la suya en cuanto dominador, pero revestida ahora de una actitud paternal. De este modo se pasa del discurso dominador violento, al no-violento, al paternalista" (Roig, A. 212: 1981).

En este grupo ha mantenido un protagonismo sin igual la figura de fray Bartolomé de Las Casas. La mayoría de estudios sitúan sin embargo su origen en el "sermón del Adviento" que fray Antonio de Montesinos dictó en Santo Domingo en 1511, donde se denunciaría por primera vez públicamente el maltrato a los indios y los rumores acerca de que no se trataba de seres humanos. Al igual que el anterior este fue un grupo heterogéneo donde se dieron disparidad de opiniones, pero podemos resaltar una serie de nociones comunes. En primer lugar, se oponen a la idea de que los indígenas sean siervos por naturaleza. Llegan incluso, como hizo Bartolomé de Las Casas, a poner en cuestión el propio concepto de "servidumbre por naturaleza", planteando que Aristóteles se refería exclusivamente al orden social y político, a la naturaleza de la comunidad perfecta y no a la condición humana ${ }^{7}$, de esta forma se postulaba la libertad ontológica de todos los seres del mundo y su directa concreción material: la imposibilidad de someter a ningún ser humano a la condición de esclavo ${ }^{8}$; que era de facto a lo que habían sometido a los pueblos indígenas en las encomiendas. Los pueblos indígenas pasaban así a ser directos vasallos, nunca siervos, de Dios y sus vicarios en la tierra: el emperador y el papa. En segundo lugar plantean que nunca será justa una guerra contra los pueblos indígenas de América, llegando incluso a negar la autoridad del emperador y el papa para tener poder temporal y soberanía sobre estos pueblos y sus territorios. Que vivan en estado de paganismo, e incluso que realicen sacrificios humanos o canibalismo, no puede ser razón para hacerles una guerra justa pues son pueblos que aún no conocen el mensaje de la "verdadera fe"

\footnotetext{
${ }^{7}$ Era común en la época la referencia a Aristóteles por el status al que había elevado su figura la tradición escolástica. Su filosofía fue utilizada para argumentar cuestiones muy diferentes y hasta antagónicas por parte de diversos grupos, su pensamiento social era una de las principales fuentes de autoridad y por la tanto también de derecho.

${ }^{8}$ Bartolomé de Las Casas sólo llegó a expresar tal radicalidad de su pensamiento al final de su vida, arrepintiéndose de haber desdeñado en el pasado a grupos humanos como los africanos.
} 
y que nunca han ido al territorio de la cristiandad con intenciones belicosas ${ }^{9}$. En tercer lugar plantean que para la realización de la más santa misión -y la auténtica y más alta legitimación jurídica de la conquista- de la evangelización de estos pueblos, nunca se podrá realizar mediante métodos violentos, pues estos generan un resentimiento y una desconfianza que podría derivar en el fracaso de la tarea como sucedió con los "moriscos" (árabes conversos) y los "marranos" (judíos conversos) en la Península Ibérica. La evangelización tenía que ser lenta y pacífica para que pudiera dar sus más altos frutos, demostrando desde la propia rectitud de la vida de los monjes, con el propio ejemplo, los más altos valores de la convivencia y el sentido del mundo del cristianismo.

Al menos dos divergencias existieron en el seno de este grupo. En un primer lugar puede analizarse en la discusión que mantuvieron sobre la tarea evangelizadora fray Toribio de Benavente, alias Motolinia, y fray Bartolomé de Las Casas. Bajo el punto de vista del primero la teoría radical de la evangelización pacífica de Las Casas era inviable en la práctica y la matanza de misioneros que habían ido por su propia cuenta a evangelizar pueblos del norte de México sin el apoyo de militares lo atestiguaba. Para Motolinía se justificaba el uso de la fuerza en caso de que los pueblos indígenas se negaran a escuchar el mensaje de la "verdadera fe" y para Bartolomé de Las Casas nunca se justificaba y, pese a que fuera ardua, la tarea del misionero era conseguir entrar en las comunidades y en su convivencia con ellas dar un buen ejemplo con el que finalmente convencer de los dictados del verdadero Dios, sólo así se podría conseguir una auténtica conversión. La utopía de Las Casas fue finalmente materializada en proyectos como el de las reducciones jesuitas donde se mantenía un respeto a las culturas, lenguas y organizaciones locales y bajo una tutela espiritual de los monjes se iba enseñando el mensaje de Dios a la vez que se organizaba un sistema productivo encaminado a la construcción de la comunidad perfecta (y de la acumulación de capital). En un segundo lugar, podemos observar en los escritos del padre Sahagún la desconfianza ante el método de evangelización pacífica dada la tendencia de los pueblos indígenas a llenar con sus propios contenidos las imágenes cristianas, algo que en nuestra actualidad ha tratado de comprenderse con las categorías de mestizaje, sincretismo, antropofagia cultural o codigofagia.

Esta fórmula de "evangelización pacífica" restaba poder a la autoridad imperial, las iniciativas privadas (encomenderos) y al clero secular en la tarea de la conquista y otorgaba gran poder de maniobra en el continente a las órdenes mendicantes. Con el tiempo este poder de las órdenes, sobre todo el de la jesuita, pasó a ser también un gran poder político y económico que las

\footnotetext{
${ }^{9}$ Los iustus hostis, como los árabes y los cristianos paganos o herejes, eran aquellos que aún conociendo el mensaje de la "verdadera fe" optaban por seguir otros credos e, incluso, atacaban territorialmente a la cristiandad. Contra ellos sí era justa la guerra se viera desde donde se viera, como defensa del mundo de la cristiandad llegando a la categoría de "guerra sagrada".
} 
Reformas Borbónicas trataron de exterminar sin total éxito, dado que desde las independencias hasta nuestros días mantuvieron una alta posición social y una fuerte vinculación a la reproducción del poder político. De hecho, se les considera actores centrales en la filosofía y la práctica de las independencias americanas, tanto por sus ideas como por su método de difusión de las mismas, materializado en una educación superior de alto nivel hacia los hijos de los líderes indígenas y los criollos. De una u otra manera nadie desconoce el poder de la educación de las órdenes, y de la jesuita en particular, en el continente americano.

Mantener una postura de crítica frontal ante este grupo de intelectuales es una tarea delicada. Se trata de oponerse a algunos de los planteamientos de grandes autores y autoras comprometidas con la región a quienes respetamos en alto grado y cuyas batallas políticas compartimos en gran medida ${ }^{10}$. Aunque ese tampoco es un gran problema, pues el debate y la crítica son un fruto ardiente y fructífero tanto para el pensamiento como para liberación de Nuestra América. Sin embargo, un posicionamiento radical en contra de este grupo de intelectuales puede llevarnos a caer en posturas anti-identitarias, propias de un posmodernismo carente de una reflexión política a la altura de la realidad y de los acontecimientos en nuestro continente. Tenemos que enfatizar que estas ideas, expresadas por los frailes bajo los intereses concretos mencionados, han sido utilizadas a lo largo de la historia por diversos movimientos populares para legitimar sus levantamientos y luchas sociales frente a la opresión colonial. El rastreo de esta cuestión es sencillo, véase el encumbramiento generalizado por parte de algunos movimientos y sus líderes de las ideas y acciones de Bartolomé de Las Casas o Vasco de Quiroga (a quien Francisco de Miranda llamó "varón universal"). El uso estratégico de estos posicionamientos y sus frutos no pueden desdeñarse de un modo tajante en nuestro contexto. Pero nos inclinamos por el rastreo de genealogías más cercanas a los postulados de los movimientos e ideas de liberación propias de la región que escapen a la idea tutelar que nunca se pone en duda en estos intelectuales. Esta caridad esconde dominación y un trato bochornoso para quien la recibe, que no respeta los fundamentos de su vida. Situar a estos intelectuales como el comienzo de una conciencia crítica americana es erróneo, encubre la lógica tutelar que en sus acciones operaba y sus intereses concretos de "conquista pacífica". Las ideas

${ }^{10}$ Una revisión de esta posturas en la actualidad puede encontrarse en Mauricio Beuchot (véase: Beuchot, Mauricio (1994) Los fundamentos de los Derechos Humanos en Bartolomé de las Casas, Bogotá: Siglo del Hombre), Enrique Dussel (2012) y Mario Ruiz Sotelo (2010). Frente a ellos estarían posturas como la de Arturo Andrés Roig que señala el paternalismo implícito en el pensamiento de Bartolomé de Las Casas (véase: Roig, Arturo Andrés (1981) Teoría y crítica del pensamiento latinoamericano, México: FCE) o las de Eduardo Subirats cuya critica radical frente al pensamiento de Bartolomé de Las Casas desvela las profundas conexiones con el espíritu moderno y colonial del pensamiento del fraile (véase: Subirats, Eduardo (1994) El continente vacío. La conquista del Nuevo Mundo y la conciencia moderna, México: S. XXI).

Araucaria. Revista Iberoamericana de Filosofía, Política y Humanidades, año 18, n ${ }^{\circ} 36$. Segundo semestre de 2016. Pp. 87-110. ISSN 1575-6823 e-ISSN 2340-2199 doi: 10.12795/araucaria.2016.i36.05 
toman realidad sólo en la historia y en los sujetos que las materializan. El uso que de estos posicionamientos pudo tener Túpac Amaru no puede compararse con el de Bartolomé de Las Casas, pese a que existan influencias retóricas, su fondo, su espíritu y su materialidad parten de coordenadas de existencia y anhelos de mundo antagónicos. Hilar fino las trayectorias de las prácticas y filosofías de resistencia de nuestros pueblos frente a la opresión colonial es un camino poco explorado que es indispensable recorrer para estar a la altura de las luchas de nuestro tiempo.

\subsection{Los que prevalecen}

Pese a que la historiografía clásica nos ha presentado el problema entre el grupo de los que atacan y el grupo de los que defienden considero que hubo un grupo más que fue el que produjo las ideas que realmente prevalecieron en la política cotidiana. Generalmente se les ha catalogado de posiciones intermedias. Bajo mi punto de vista tanto por sus planteamientos éticos y por su método y forma de trabajar las ideas - que podríamos denominar pragmática-podemos clasificarlos como un grupo propio. Este sería el grupo liderado por fray Francisco de Vitoria ${ }^{11}$. Sus postulados éticos podrían parecer estar más cerca del grupo de "los defensores", pero también dieron argumentos para actividades de conquista que sirvieron a los intereses de los grupos de "los atacantes". Esto ha sido interpretado y caracterizado como "duda que ofende" (Ruiz, M. p. 86 y Ss.: 2010), ambivalencias derivadas de la presión política (Rovira, M. C. 116: 2004) o como posturas conciliadoras (Grice-Hutchinson, M. 63: 1995). Bajo mi punto de vista también es el fruto de un método de trabajo basado en lo que ha sido conocido como el primer intento de abstracción del derecho de gentes y el nacimiento del derecho internacional.

Francisco de Vitoria bebió del espíritu humanista de su tiempo para tratar de establecer leyes generales en las relaciones de los pueblos, y en concreto en las referentes a las acuciantes problemáticas derivadas de la conquista de América, basadas en los preceptos éticos y jurídicos del mundo cristiano. Esta forma de trabajar alumbró suspicaces críticas como la primera realizada a la idea de "descubrimiento" que sagazmente fue presentada aludiendo a que pudieron haber sido los indios los que "descubrieran" a los europeos. Es decir, lo que pudieran hacer los europeos también podían hacerlo los indígenas y no existía un principio de separación tan claro entre los unos y los otros bajo las leyes del derecho natural pese a que la política colonial estuviera basando sus instituciones políticas en la idea de separación en dos "repúblicas". Lo que había que reglar eran las relaciones entre los pueblos, las causas de justa guerra entre

${ }^{11}$ Francisco de Vitoria no participó expresamente en la controversia de Valladolid pero sus ideas expresadas a través de sus Relecciones fueron muy divulgadas y tomadas en cuenta en la época.

Araucaria. Revista Iberoamericana de Filosofia, Política y Humanidades, año 18, no 36. Segundo semestre de 2016. Pp. 87-110. ISSN 1575-6823 e-ISSN 2340-2199 doi: 10.12795/araucaria.2016.i36.05 
ellos, y no tanto la idea de que unos pudieran ser sujetos de derechos y otros no. El anhelo de Vitoria era universal. Este fue un falso universalismo basado en la expansión de las condiciones concretas de la cosmovisión cristiana y escondía relaciones de poder que se habían establecido en la conquista. Por ejemplo, algunos de los derechos inalienables y universales serían los derivados del ius commercci y el ius peregrinandi donde el comercio entre los pueblos y la libre peregrinación de los hombres en los diferentes territorios si era pacífica no podía ser negada. Pero, obviamente los indígenas no tenían la capacidad ni el interés de ir a Europa a comerciar o peregrinar... de esta forma se inauguraba el fetiche jurídico que aun hoy en día sigue siendo tan patente en el derecho internacional.

Esta tendencia universalista, que escondía la expansión de los ideales de vida cristianos y ponderaba a los hombres bajo una falsa idea de igualdad en un mundo cuya diversidad civilizatoria estaba siendo conquistada y destruida por la cristiandad, fue la que se impuso inaugurando el comienzo de una concepción legalista de lo jurídico que bajo una idea de "ciencia" encubría las relaciones de dominación. Francisco de Vitoria y este grupo de intelectuales hispanos inauguraron aquello contra lo que la teoría marxista del derecho nunca ha dejado de criticar: el fetiche jurídico como esencia del derecho moderno.

"Disertaré ahora sobre los títulos legítimos e idóneos, por los que pudieron los bárbaros venir a poder de los españoles

1. EL PRIMER TÍTULO puede nombrarse de la sociedad y comunicación natural.

2. Y acerca de esto sea así la PRIMERA CONCLUSIÓN: "Los españoles tienen derecho a recorrer [ius peregrinandi] aquellas provincias $y$ de permanecer alli sin que puedan prohibírselo los bárbaros, pero sin daño alguno de ellos [...]

3. Es lícito a los españoles comerciar con ellos [ius commercci], pero sin prejuicio de su patria, importándoles los productos de que carecen y extrayendo de allí oro y plata y otras cosas en que ellos abundan [...]

4. Si hay cosas entre los bárbaros que son comunes, tanto a los ciudadanos como a los huéspedes, no es lícito a los bárbaros prohibir a los españoles la comunicación y participación de esas cosas $[\ldots]$

6. Si los bárbaros quisieran negar a los españoles las facultades arriba declaradas de derecho de gentes, como el comercio y las otras cosas dichas, los españoles deben, primero con razones y consejos, evitar el escándalo y 
mostrar por todos los medios que no vienen a hacerles daño [...] Más si, dada razón de todo, y si los bárbaros no quieren acceder, sino que acuden a la violencia, los españoles pueden defenderse y tomar todas las precauciones que para su seguridad necesiten; porque lícito es rechazar la fuerza con la fuerza. Y no sólo esto, sino también, si de otro modo no están seguros, construir fortificaciones y defensas; y si padecen injuria, pueden con la autoridad del príncipe vengarla con la guerra, y llevar adelante los demás derechos de la guerra" (Francisco de Vitoria 59-63:2007, negritas mías)

Si los pueblos indígenas violan estos "derechos comunes" que les están perjudicando, ya que son caracterizados como universales a todos los pueblos, será justo hacerles la guerra e imponerles por la fuerza aquello que es "común" y que también les "pertenece" a ellos, es decir, "por su propio bien y el de toda la comunidad". Un postulado que se ha seguido manteniendo hasta nuestros días donde en nombre de la civilización, los derechos humanos, el derecho internacional o la democracia se han invadido y despojado países enteros por su propio bien y el de toda la comunidad internacional.

Es por estas aseveraciones que se ha tomado el pensamiento de Francisco de Vitoria como la primera apertura tanto hacia el derecho internacional como hacia la legitimación del capitalismo como sistema mundial como plantea Enrique Dussel (Dussel, 207: 2007). Esta interpretación del pensamiento de Francisco de Vitoria como el pionero de un pensamiento jurídico mercantilista no es actual y ha estado presente desde hace mucho tiempo en los análisis de los historiadores del derecho. Ante ello Carl Schmitt plantea que esa interpretación ha sido origen del uso posterior por parte de juristas como Hugo Grocio de ciertas partes del pensamiento de Vitoria desconectadas del fondo ético que defendía el fraile. Para Schmitt las ideas de Francisco de Vitoria se dirigen a legitimar la misión papal de evangelización de los territorios descubiertos y es bajo esa lógica desde la que plantea sus argumentos y no como la apertura legal de los mercados internacionales:

\footnotetext{
"El derecho al liberum commercium y el ius peregrinandi son, para Vitoria, un medio de ejercer la libre misión del cristianismo y de llevar a cabo un encargo papal de misión; no es lo mismo que el principio de la puerta abierta para una penetración industrial, ni tampoco debe confundirse la exigencia de la libre propaganda basada en el Evangelio -San Mateo, 28, 29- con una renuncia relativista o agnóstica a la verdad. Aquí sólo nos interesa la justificación de la toma de tierra, una cuestión que Vitoria reduce al problema general de la guerra justa. Todas las cuestiones importantes de una ordenación basada en el Derecho de Gentes convergen, en último término, en el concepto de la guerra justa" (Schmitt, C. 98: 2002).
}

Se trataba de generar nociones y derechos comunes universales que el fraile comenzaba a expresar también en términos abstractos y ahistóricos. Estas 
ideas le llevaron a enfrentarse con la Corona, pues algunos de los elementos que proclamaba como universales se enfrentaban a los intereses de la conquista, pero también a confrontarse con sus colegas frailes "defensores de los indios", pues algunos de los elementos postulados daban legitimidad a la Conquista ${ }^{12}$. Esta contradicción se explica porque Francisco de Vitoria comenzó a construir de modo abstracto los postulados comunes a los pueblos. Este ejercicio nunca lo realizó con ese afán, sino con el de tratar de ser lo más fiel posible a Dios y su derecho divino expresado a través del derecho natural en relación con el cumplimiento de la misión papal de evangelizar y convertir al cristianismo a todo el orbe. Para él siguieron siendo indispensables las diferenciaciones entre cristianos y no-cristianos, pese a que el derecho de gentes afectara por igual a unos y otros. Una vez hecho este movimiento, aunque no fuera con aquella intención, abrió la puerta para la universalización total y la igualdad jurídica formal que escondería una desigualdad de génesis sustancial. Carl Schmitt nos dice al respecto:

"Vitoria no formaba parte de los eruditos que, en cuestiones de la existencia del cristianismo, sostenían un punto de vista puramente formal -a favor o en contrade neutralidad interior, y acerca de los cuales dijo un hegeliano especialmente crítico del siglo XIX que eran los precursores de los abogados modernos de fórmulas constitucionales. Pero no puede negarse que su método ahistórico, que se abstrae totalmente de puntos de vista espaciales, revela a ciertos conceptos históricos europeos, como pueblo, príncipe, guerra, que son específicos del Derecho de Gentes de la Edad Media cristiana, de su lugar histórico y los priva así de su particularidad histórica. De esta manera, la teología puede convertirse, en un principio, en una doctrina moral general, y ésta, por su parte -con ayuda de un ius gentium igualmente generalizador- en una doctrina moral natural en el sentido moderno y en un mero derecho de la razón. Como evolución lógica de este inicio emprendido en la escolástica tardía, filósofos y juristas de los siglos XVII y XVIII posteriores a Vitoria y Suárez -desde Grocio a Cristian Wolff- desarrollaron un ius naturale et gentium puramente humano, aún más generalizado y neutral. Estos filósofos y juristas ya no tomaban en consideración la diferencia entre cristiano y paganos, la cual era esencial para el dominico español. Así se hacía posible poner los argumentos de Vitoria al servicio de objetivos diferentes y de intenciones políticas distintas e incluso opuestas" (Schmitt, C. 91: 2002).

\footnotetext{
${ }^{12}$ Las posiciones ambiguas de Francisco de Vitoria frente a la defensa de los indios son interpretadas en el estudio de María del Carmen Rovira (2004) como una postura de miedo que tuvo el fraile ante posibles amenazas de la potestad regia. Según la autora, Francisco de Vitoria estaría más cerca de la defensa de los pueblos indígenas y contra los abusos de los conquistadores como se demuestra en las relecciones anteriores a su afamada "De Indis", donde explicita las causas de guerra justa dando argumentos para poder efectuarla frente a los pueblos de América.
} 
Desde otros puntos de vista, historiadoras del pensamiento económico como Marjorie Grice-Hutchinson ${ }^{13}$, tratando de aislar de cierta forma (ya que en estos autores no se presentaba nada de forma separada) las tesis económicas de Vitoria y sus seguidores, han planteado que se encuentra en ellos una primera teoría del valor monetario basada en una "estimación común" abstracta (Grice-Hutchinson, M. 54: 1995) como resultado de la posición geopolítica en la que se encontraban inmersos. Se trataría de un posicionamiento que trataría de compaginar las leyes morales propias de la Escolástica con la creciente ampliación del poder del Imperio hispano y sus clases mercantiles que resultaban del saqueo del continente americano:

\begin{abstract}
"Cuando la Escuela de Salamanca había quedado ya muy atrás y el escolasticismo había dejado de dominar la forma de pensar de las personas, esta visión subjetiva del valor, o fundada en la utilidad, fue preservada y comunicada a través de generaciones sucesivas hasta que llegó a ser una de las bases de la ciencia económica moderna. Los salmantinos, naturalmente, no podían saber que en su obra latían las semillas del liberalismo económico, y tampoco podemos afirmar cuál habría sido su reacción si lo hubiesen sabido. La relevancia de la teoría monetaria de Salamanca para nuestro tiempo ha sido importante. Pero, por una de esas paradojas que alegran la historia del pensamiento económico, fue algo fortuito e incidental con relación dos grandes objetivos de los doctores: mantener la autoridad del derecho canónico y al mismo tiempo aliviar la condena moral que pesaba sobre las conciencias de los comerciantes" (Grice-Hutchinson, M. 62/63: 1995).
\end{abstract}

Esta fue la fórmula por la que la imposición del derecho natural europeo cristiano fue poco a poco universalizándose y presentándose como común a toda la humanidad desde una base secular y científica, supuestamente voluntarista e incluyente de la diversidad, como la que se nos presenta en nuestro derecho internacional actual. El despojo y el genocidio de los pueblos de América forman parte fundamental de la génesis del derecho internacional.

\footnotetext{
${ }^{13}$ Siguiendo las tesis de su maestro F.A. Hayek, la investigación de Marjorie Grice Hutchinson está dirigida a encontrar los orígenes del liberalismo y aquella razón de la "riqueza de las naciones" en el pensamiento económico hispano del s. XVI en relación al "descubrimiento" de América. Su trabajo, muy erudito, se presenta con un halo de neutralidad científica que encubre su posicionamiento de profunda creencia en las leyes abstractas del mercado y la acumulación de capital como fuente del progreso humano.
} 


\section{Conclusiones:}

"La caridad es humillante porque se ejerce verticalmente y desde arriba; la solidaridad es horizontal e implica respeto mutuo"

Eduardo Galeano

Así como la teoría crítica radical negra desenmascaró la abolición de la esclavitud como un proceso que respondía a factores de transformación en los sistemas de poder más que a un supuesto espíritu de benevolencia occidental, véanse entre otras las obras de Eric Williams y C.L.R. James, podemos afirmar que pasó algo similar con los frailes llamados defensores de los pueblos indígenas en el siglo XVI. Su defensa estaba dentro de un marco de consideración de la naturaleza inferior de estos pueblos, considerados como pueblos "sin secta" (sin religión), y, pese a que se intentara enmascarar, el principio de evangelización nunca se puso en duda. Además, la supuesta defensa formaba parte del engranaje geopolítico imperial del Vaticano y la cristiandad. La disputa tradicionalmente presentada entre Sepúlveda y Las Casas representa dos caras de la misma moneda, la del colonialismo, la de una nueva organización de la economía política y la fuerza de trabajo en torno a criterios raciales, ya sea en una versión fuerte (Sepúlveda) o light (Las Casas).

De esta forma, hemos caracterizado tres grupos de posturas en la llamada controversia de Valladolid de 1550-1551: la capitaneada por Sepúlveda coincidía con los intereses de los encomenderos porque legitimaba el despojo de tierras de los pueblos indígenas; la de Las Casas con los intereses del Vaticano porque legitimaba la evangelización pacífica, cuidando de que no exterminaran a los pueblos indígenas, considerados bajo este paradigma como un gran banco de fieles y la posibilidad de salvación de la cristiandad ante el avance de la herejía en Occidente; y la de Vitoria, que la hemos incluido por su impacto en la misma época y contexto aunque no participara en persona en la controversia, con los intereses de los imperios que buscaban la expansión comercial mundial, ya que defendía los derechos a la libertad de comercio de los imperios cristianos, presentados como fórmulas abstractas e ideales. Cada una tuvo mayor o menor impacto según la época, contextos y grupos sociales, y todas ellas fueron utilizadas a lo largo de la historia para justificar políticas y acciones diversas a favor y en contra de los pueblos indígenas.

Lo que hemos tratado de demostrar aquí es que todas ellas respondían a un mismo patrón de poder, el poder de la cristiandad, y la controversia, si es que la había, no era sobre si los indígenas eran humanos o no, sobre si había que defenderles o atacarles, sino que consistía en establecer los alcances, límites y modelos de organización de un hecho muy claro y concreto: la conquista 
material y espiritual del continente americano y sus habitantes, la disputa sobre los modos de organización y dominio de la fuerza de trabajo superexplotada indígena dentro del régimen colonial hispanoamericano.

Todo ello legitimado en el fundamento de que se trataba de pueblos retrasados, en estado de naturaleza, sin religión, etc. necesitados de una tutela permanente, por lo que, por "su propio bien", serían evangelizados, indoctrinados, saqueados, colonizados, despojados y/o conquistados de forma pacífica y/o violenta por parte de una civilización que se consideraba así misma superior, capaz de categorizarlos como pueblos inferiores y, sobre todo, capaz de "enseñarles" un supuesto mundo mejor mediante su subyugación en aras de la consecución de un "bien común" enunciado en abstracto, que en la práctica era el bien común concreto de quienes colonizaban y conquistaban. Esta forma de dominio legitimada en la idea de la necesidad de una "tutela permanente", "necesaria por naturaleza", es muy similar a la ejercida sobre las mujeres bajo el patriarcado de la sociedad occidental, quienes pasan de la tutela de su padre a la tutela de su marido sin posibilidad de emancipación debido a la concepción patriarcal que categoriza su naturaleza como "débil" e “inferior”. Esta intersección entre racismo y patriarcado ha sido señalada por varias teóricas y activistas inscritas en los feminismos indígenas, comunitarios y descolonizadores de América Latina, pero necesitaríamos de otro espacio para seguir abordando la importancia de este nexo. 


\section{Referencias bibliográficas:}

Baudot, Georges (1996) "Imagen amerindia y proyecto utópico: Motolínea y el discurso milenario" en México y los albores del discurso colonial, México: Nueva Imagen, pp. 245-266.

Beuchot, Mauricio (1994) Los fundamentos de los Derechos Humanos en Bartolomé de las Casas, Bogotá: Siglo del Hombre.

Castilla Urbano, Francisco (1995) "El concepto de "estado de naturaleza" en la escolástica española de los siglos XVI y XVII” Anuario de filosofía del derecho, $\mathrm{n}^{\mathrm{o}} 12$, pp. 425-445.

Colón, Cristobal (2009) Diario de a Bordo, Madrid: Dastin. [Original de 1492] Dussel, Enrique (1994) El encubrimiento del indio: 1492 (Hacia el origen del mito de la modernidad), México: Siglo XXI.

(2012) Política de la liberación. Historia mundial y crítica, Madrid: Trotta.

Gallegos Rocafull, José María (1974) El pensamiento mexicano de los siglos XVI y XVII, México: UNAM.

Grice-Hutchinson, Marjorie (1995) Ensayos sobre el pensamiento económico en España, Madrid: Alianza.

Grosfoguel, Ramón (2013) "Racismo/sexismo epistémico, universidad occidentalizadas y los cuatro genocidios/epistemicidios del largo siglo XVI" en Tabula Rasa, no 19, pp. 31-59.

Guerrero, Ana Luisa (2014) Filosofía Política y Derechos Humanos, México: UNAM.

Hanke, Lewis (1974) El prejuicio racial en el Nuevo Mundo. Aristóteles y los indios de Hispanoamérica, México: SEP.

Hicks Gómez, Eva (1984) "Las Misiones Culturales Rurales: un proyecto de alfabetización para la integración” en Revista de Educación, Vol. II n ${ }^{\circ} 3$, Julio-Septiembre, México: Secretaría de Educación Pública.

Maldonado-Torres, Nelson (2005) "Religion, Conquest, and Race in the Foundations of the Modern/Colonial World" Unpublished draft paper, nd, pp. 3-4.

Milhou, Alain (1998) "América frente a los sueños orientales (1492-principios del siglo XVII)" en Jean Cannavagio (Ed.) España y América en una perspectiva humanista. Homenaje a Marcel Bataillon, pp. 141-218, Madrid: Casa de Velázquez.

Rama, Ángel (1984) La ciudad letrada, Ediciones del Norte: Buenos Aires.

Rancière, Jacques (2002) El maestro ignorante, Barcelona: Laertes.

Rodríguez, Jimena (2010) Conexiones transatlánticas: viajes medievales y crónicas de la conquista de América, México: COLMEX.

Rodríguez Torres, Adriana (2007) "Utopías y crónicas de Indias: una 
construcción recíproca" en Karl Kohut (Coord.) Narración y reflexión: las crónicas de Indias y la teoría historiográfica, México: COLMEX, pp. 219-243.

Roig, Arturo Andrés (1981) Teoría y crítica del pensamiento latinoamericano, México: FCE.

Rovira, Carmen (2004) Francisco de Vitoria. España y América. La palabra y el hombre, México: Miguel Ángel Porrúa.

Ruiz Sotelo, Mario (2010) Crítica de la razón imperial. La filosofía política de Bartolomé de Las Casas, México: Siglo XXI.

Schmitt, Carl (2002) El nomos de la tierra en el Derecho de Gentes del "Ius publicum europaeum", Granada: Comares. [Original de 1950].

Sepúlveda, Juan Ginés (1985) Tratado sobre las justas causas de la guerra contra los indios, México: FCE. [Original de 1557]

Sierra, Augusto Santiago (1973) Las misiones culturales, México: Secretaría de Educación Pública.

Soto, Domingo (1985) "Controversia Las Casas - Sepúlveda" en José Alcina Franch (Ed.) Obra Indigenista, pp. 163-281, Madrid: Alianza Editorial. [Original de 1550]

Vitoria, Francisco (2007) Relecciones del estado, de los indios, y del derecho de la guerra, México: Porrúa. [Original de 1532] 